\title{
Generation Expansion Planning Considering Competition and Market Power
}

\author{
Saltuk Bugra Selcuklu ${ }^{1,2 *}$, Ayman Isam Elzein Elmahi ${ }^{3}$
}

\author{
${ }^{1}$ Energy Systems Engineering, Erciyes University, Kayseri, TURKEY \\ ${ }^{2}$ Energy Conversion Research and Application Center, Erciyes University, Kayseri, TURKEY \\ ${ }^{3}$ Independent Researcher, SUDAN \\ *Corresponding Author: sbselcuklu@erciyes.edu.tr
}

Citation: Selcuklu, S. B. and Elzein Elmahi, A. I. (2022). Generation Expansion Planning Considering Competition and Market Power. European Journal of Sustainable Development Research, 6(1), em0176. https://doi.org/10.21601/ejosdr/11409

\section{ARTICLE INFO}

Received: 30 Jun. 2021

Accepted: 28 Oct. 2021

\begin{abstract}
One of the main goals of establishing electricity markets is to increase efficiency, and another is to lower the prices of electricity by ensuring competition. Protecting and improving the competitive environment of the market help in achieving these goals. If any of the generation companies in the market can exercise market power, the competition will then decrease and may even disappear. This study offers an optimization model minimizing the market power of all companies. The model can be utilized from the beginning of the liberalization of the electricity sector or during the transformation process from the monopoly to the competitive markets. It is a mixed-integer linear programming model where the bi-level structure of the problem is transformed so that the lower-level and the upper-level are combined in a single level. The lower-level model minimizes investment and production costs of companies. The upper-level maximizes the competition between all companies by minimizing market power. A numerical example is presented and discussed to test the effectiveness of the proposed model and to evaluate the results. Two scenarios are examined in which companies do and do not have budget restrictions. The results show that the model works successfully in both scenarios, and the market power of all companies is decreased so that none can distort competition. However, the second scenario, in which the state-owned company has a budget limit, is more successful in terms of satisfying not only the state and private companies but also consumers. The companies that were small at the beginning have higher shares in the second scenario and the shares of bigger companies are decreased significantly. Also, the second scenario was able to meet the investment needs from a lower level, and investments were shifted to private firms, thus saving investment expenditures of both government and private firms. Furthermore, in both scenarios, prices tend to decrease toward the target year, but the second scenario can keep prices much lower.
\end{abstract}

Keywords: Generation Expansion Planning (GEP), competitive electricity markets, competition maximization, market power minimization

\section{INTRODUCTION}

Energy use at the world level will increase progressively until 2030 and probably beyond. A study by the French Association of Oil Professionals (Pedraza, 2015) mentions that the world demand for energy will be expected to be double in 2030 , and it may triple in 2050. In addition, the primary energy demand at the world level will increase by $1.7 \%$ annually until 2030 (Pedraza, 2015). Electricity demand will also increase since the electrification of nearly all sectors and industries is rapidly developing. The increasing electricity demand must be met by new investments. Strategic planning is crucial to determine the most appropriate technology, the expansion size of these technologies, and the timing of the construction.
This problem is known as the Generation Expansion Planning (GEP) problem.

There are many studies on GEP problems. Numerous reviews on the subject will reveal the importance of the subject. A few of the extensive reviews are Hobbs (1995), Kagiannas et al., (2004), Hemmati (2013), and Sadeghi et al. (2017).

Classical GEP models assume the central planning perspective because the electricity generation sector is used to be regulated and under the control of a central authority such as a government company or a system operator corporation. Both the investment and generation decisions are taken by the same decision-maker. Therefore, classical GEP models are usually single-level, single-objective, linear, or mixed-integer programming models. However, in the last two decades, the electricity sector has been deregulated in many countries and 
competitive electricity markets are opened. In the market environment, there are several investor and generation companies (GENCOs) besides the system operator. In this new setting, there are several decision-makers with different perspectives and objectives. For example, GENCOs want to maximize their profit from the electricity trade. On the other hand, the system operator or the government aims to provide affordable and reliable electricity service. Therefore, the mathematical formulation of the problem is also evolved. Mathematically, the investment planning model in electricity generation markets is classified as a bi-level model since an optimization problem is constrained by other optimization problems such as in the following studies. Valinejad et al. (2018a) present a stochastic bi-level model. In the first level, producers try to find the optimized decisions related to investment and then provide their offers to the spot market to maximize their total profit. Market-clearing is presented at the second level where the priority is to maximize social welfare. Zhan and Zheng (2018) present a bi-level problem in the longterm GEP. A multistage stochastic upper-level problem is used to maximize the expected profit and investment decisions are made for wind and thermal generators. Ghaderi et al. (2014) present a bi-level problem where the upper-level model maximizes the total profit of power plants while the lowerlevel problem maximizes social welfare. Wogrin et al. (2011) present a bi-level model to separate investment decisions from generation decisions. In the upper-level model, investment decisions of a single GENCO are taken to maximize expected profits. In the lower-level model, the generation decisions of all companies are presented. Wang et al. (2009) present a game model in the form of a bi-level optimization model. In the upper model, each GENCO must model the information of other GENCOs to maximize its profit and if the GENCO does not model the information of other GENCOs, the profit of this GENCO could be lower. In the lower-level model, the Independent System Operator (ISO) is responsible for marketclearing to minimize the operation cost with the presence of inelastic demands while considering the reliability requirements of the supply system. Kazempour et al. (2010) propose a bi-level model. In the upper-level model, each strategic producer seeks to maximize the profit subject to investment options. The lower-level model corresponds to market-clearing. Each lower-level model (one per demand block and scenario) maximizes the social welfare where the market is cleared according to the power balance at every bus, power limits for consumption and transmission, and production constraints. Wogrin et al. (2012) present a bi-level multi-year equilibrium model. In the upper-level model, GENCOs maximize their profits. The lower-level model represents the market by using the approach of conjecturedprice response which allows varying the behavior of the strategic spot market to show how this behavior impacts the investment decisions. Valinejad et al. (2018b) present a novel bi-level model. In the first level, there are steps related to investment incentives such as firm contract and capacity payment used to maximize the profit. The second-level model focuses on maximizing social welfare. Rafiei et al. (2019) present a bi-level model. At the upper level, a strategic offering is presented to maximize the profits of wind turbines investor and compressed air storage systems, while at the lower level, the ISO increases the social welfare. Romero et al. (2019) propose a bi-level model for the coordination of generation and transmission problems. A centralized transmission system operator (TSO) is present at the upper level, while decentralized GENCOs that trade in the market are presented at the lower level. Wang and Chen (2019) propose a bi-level model where the upper level simulates the process of the decision-making of the investor to maximize the profit through investment management, optimal energy sales, and risk management. In the lower level, the decision-maker is the ISO, who determines the locational marginal prices and runs the economic dispatch for the transmission system. Liu et al. (2020) propose a bi-level model to provide a suitable solution for transmission lines expansion and generators retrofit. The upper model presents the decision of the network line extension considering investment constraints. Based on the new network from the upper layers, the lower level calculates the capacity and site of thermal power units. Wang et al. (2020) develop a stochastic bi-level mixed-integer model to investigate the wind generation planning problem in the case of the electricity market and the operations of topology control. The system planner in the upper level seeks to find the optimal sizing and siting of new wind farms to maximize the absorption of wind energy and minimize the investment cost. In the lower-level model, the absorption of wind energy is determined by the market-clearing problem to minimize the dispatch cost with the grid configurations. Table 1 summarizes the first and second-level objectives of the reviewed bi-level models.

In the literature, there is no study in which competition maximization is considered as the objective function of electricity generation capacity expansion planning. As in the studies reviewed above, models for maximizing the profit of companies or increasing general economic welfare are in the majority. However, there are many studies on the examination of the competitiveness of the markets. The majority of these studies are the ex-post analysis, that is after the markets are established and started to operate. These studies are usually economic studies without an optimization or planning perspective. Some of these studies are discussed below.

Nazemi and Mashayekhi (2015) examine the production efficiency at high-demand moments to assess the Iranian regulated electricity market's progress towards competitiveness. They compare their output with the ex-post data. Growitsch and Nepal (2009) evaluate the effectiveness of the German wholesale electricity market in the context of price adjustments, the price-setting process, and the speed of this process using the cointegration analysis and error verification model. As a result of their analysis, they showed that the market is ineffective and does not work well. Wolak (2015) examine the effect of transmission line investments on the market competition with experimental results. Hourly electricity offers, production outputs, market price, and transmission restrictions data are used as competitive measures. This study evaluates competition based on ex-post data. Mansur (2008) proposes a new technique that models the behavior of firms and compares the competitiveness of the market with the actual data, and it is claimed that the model yields more accurate results than classical models. Mansur's technique evaluates competition based on ex-post data. Müsgens (2006) examines the degree of market power 
Table 1. Summary of the reviewed bi-level models

\begin{tabular}{|c|c|c|}
\hline Proposed by & $\begin{array}{c}\text { Upper-level model } \\
\end{array}$ & Lower-level model \\
\hline Valinejad et al. (2018a) & $\begin{array}{c}\text { Maximize the profit through optimizing the investment } \\
\text { decisions. }\end{array}$ & Maximize social welfare. \\
\hline Zhan and Zheng (2018) & Maximize expected profit. & Minimize generation cost. \\
\hline Ghaderi et al. (2014) & Maximize the total profit of power plants. & Maximize social welfare. \\
\hline Wogrin et al. (2011) & Maximize the profit of a single-generation company. & Present the generation decisions of all companies. \\
\hline Wang et al. (2009) & $\begin{array}{l}\text { Maximize the profit of the company by model information } \\
\text { of other GENCO. }\end{array}$ & $\begin{array}{l}\text { Minimize the operation cost with the presence of } \\
\text { inelastic demands. }\end{array}$ \\
\hline Kazempour et al. (2010) & Maximize the profit subject to investment options. & Present Market-clearing problem. \\
\hline Wogrin et al. (2012) & Maximize the profits of all GENCOs. & $\begin{array}{l}\text { Represents the market by using the approach of } \\
\text { conjectured-price response. }\end{array}$ \\
\hline Valinejad et al. (2018b) & Present steps related to investment incentives. & Maximize social welfare. \\
\hline Rafiei et al. (2019) & $\begin{array}{l}\text { Maximize the profits of wind turbines investor and } \\
\text { compressed air storage systems. }\end{array}$ & Maximize social welfare. \\
\hline Romero et al. (2019) & Present a centralized TSO. & Present decentralized GENCOs that trade in the market. \\
\hline Wang and Chen (2019) & $\begin{array}{l}\text { Simulates the process of the decision-making of the } \\
\text { investor to maximize the profit. }\end{array}$ & $\begin{array}{l}\text { Determines the locational marginal prices and runs the } \\
\text { economic dispatch for the transmission system. }\end{array}$ \\
\hline Liu et al. (2020) & $\begin{array}{l}\text { Presents the decision of the network line extension } \\
\text { considering investment constraints. }\end{array}$ & Calculates the capacity and site of thermal power units. \\
\hline Wang et al. (2020) & $\begin{array}{l}\text { Maximize the absorption of wind energy and minimize the } \\
\text { investment cost. }\end{array}$ & $\begin{array}{l}\text { Minimize the dispatch cost with the grid configurations } \\
\text { consideration. }\end{array}$ \\
\hline
\end{tabular}

utilization in the German wholesale electricity market through a study simulating competitive marginal costs. This technique also evaluates based on ex-post data. Shukla and Thampy (2011) use the parameters of concentration ratio, HerfindahlHirschman index, Price-cost mark-up (PCM), Residual supply index (RSI), and Supply Margin Assessment (SMA) to evaluate the competition and market power in the Indian electricity market. Parameters such as SMA and RSI demonstrate the role of each firm in meeting the electricity demand in India and therefore show whether firms have market power. The parameters used in this study are useful parameters to assess the competitive environment in the market. We use the SMA as the market power index in our model as part of the objective function which is described in the next section.

To the best of the authors' knowledge, no earlier work in the GEP literature has been reported to directly address the issue of maximizing the competition or minimizing the market power. In this paper, we present a mixed-integer linear programming (MILP) model. This model transforms the bilevel structure so that the minimization of investment and production costs and the minimization of market power are combined at a single level.

The next section describes the bi-level structure and mathematical transformations to obtain the MILP model. The third section presents the numerical example. The results are provided and discussed in the fourth section. The last section concludes the paper and outlines the future work.

\section{MODEL DESCRIPTION}

The bi-level structure incorporates the economic and technical parameters of the independent GENCOs. It optimizes the investment decisions to minimize the costs and

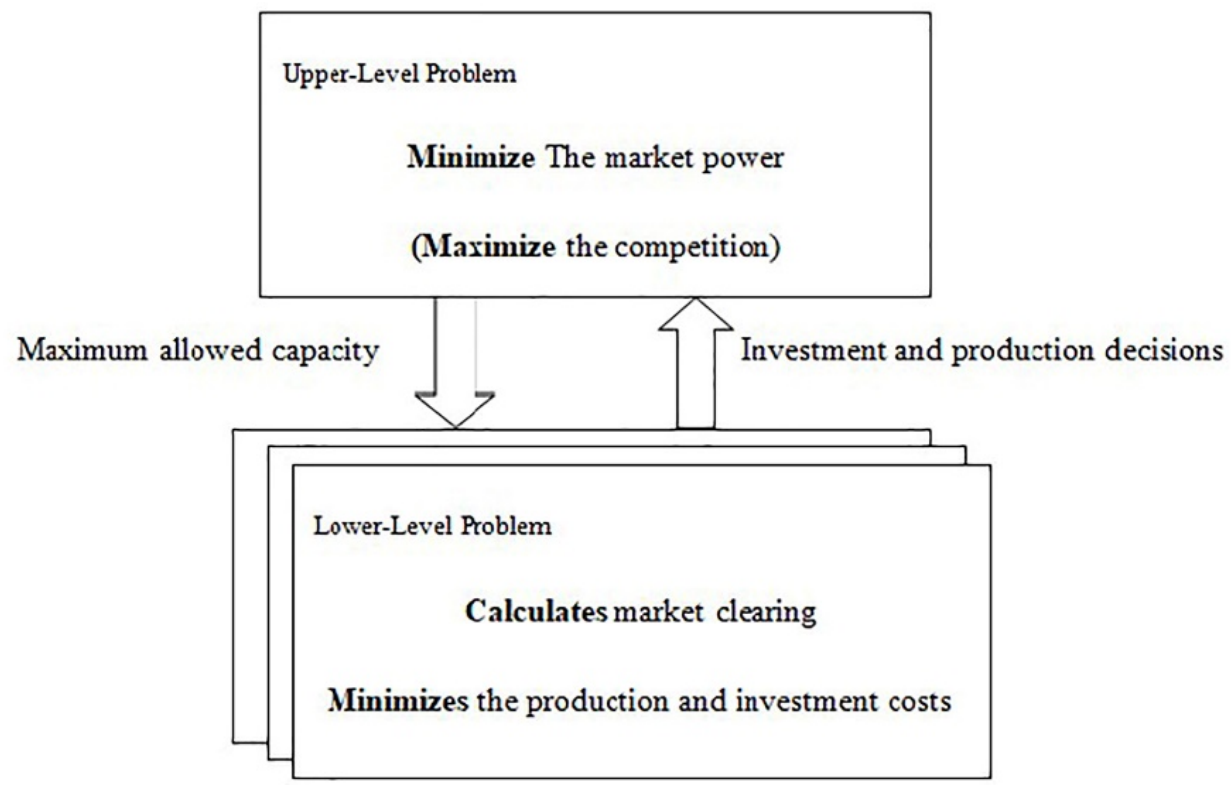

Figure 1. Bi-level structure of the proposed GEP model 


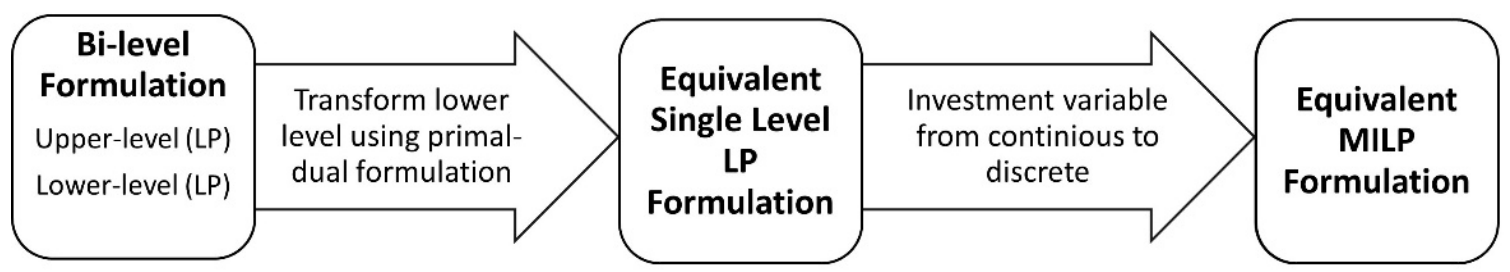

Figure 2. Transformation methodology

the overall market power to ensure that competition is maximized. The proposed bi-level structure is presented in Figure 1. The upper-level problem minimizes the market power using the investment decision. This ensures the maximization of competition in the market. The lower-level problem consists of cost minimization problems of each generation company (GENCO). This level also provides the market-clearing equilibrium. In this study, we use a transformation method, similar to Conejo et al. (2016), to remodel the bi-level structure into a single-level problem. The transformation methodology is depicted in Figure 2. The bilevel formulation is first transformed to an equivalent singlelevel linear programming (LP) model using the primal-dual formulation at the lower level. In the second step, the continuous investment decision variable is converted to a discrete variable. Lastly, the equivalent MILP model is presented. The following subsections present the mathematical formulations of each step. The resulting MILP problem is solved by the GAMS CPLEX solver.

The assumptions of the proposed model are listed as follows.

- The model is deterministic, hence, there is no uncertainty in any parameter that could affect the GEP problem. In other words, it is assumed that GENCOs have full knowledge of all parameters.

- There are no network constraints. The model determines when (the year) and how much (the capacity) we need to build new generating technology, but not where (the location) to build them.

- It is assumed that the existing capacity at the beginning is different for each GENCO. Thus, the fragmentation or shrinkage of monopoly state firms after privatization can be examined.

- It is assumed that new companies do not enter the market in the interim years.

- It is assumed that only new technologies can be preferred for investment, but by editing the input data, any number of new investment options can be offered.

\section{Upper-Level Problem}

Mathematically, the investment planning model in electricity generation markets is classified as a bi-level model since an optimization problem is constrained by other optimization problems as in Figure 1. Here, we first present the mathematical formulations of the upper-level and lowerlevel problems. Then, we will explain the transformation steps.

In order to measure the competition, the market power of companies in the market must be taken into consideration.
The objective function of the upper-level problem, Equation (1), corresponds to the minimization of market power to maximize the competition over the planning horizon ( $y$ years) for all GENCOs (indexed as $c$ ). The constraint of the upperlevel problem, Equation (2), enforces that investments over the planning horizon should not exceed the budget limits for all companies. The nomenclature is given in Table 2 .

$$
\begin{gathered}
\min \sum_{y} \sum_{c}\left(D_{y}^{p}-\sum_{j, j \neq c} \sum_{g}\left(S_{j g}^{E}+S_{y j g}\right)\right) \\
\sum_{y} \sum_{g} I_{g} S_{y c g} \leq B_{c} \forall c
\end{gathered}
$$

The first term in the objective function in Equation (1), $D_{y}^{p}$, represents the peak demand of year $y$ while the second term represents the actual installed capacity which is the sum of the existing capacity and the investments of generating unit type $g$ at year $y$ by all $j$ GENCOs except the GENCO $c$.

The objective function is the sum of the Supply Margin Assessment (SMA) indexes of all companies over the planning horizon. We use the SMA index as the market power index and it is calculated according to the following formula:

$$
\delta_{i}=D_{p}-\sum_{i} S_{-i}
$$

Here, $\delta_{i}$ is the supply margin index for firm $i, D_{p}$ is the peak demand of the market, and $S_{-i}$ is the total production capacity of all firms except firm $i$. If $\delta_{i}$ is positive for any firm, the market power of that firm is at a level that will disrupt competition.

\section{Lower-Level Problem}

The lower-level problem consists of several optimization problems where operation and investment costs of each generation company are minimized. This is also equivalent to the maximization of social welfare. This level also calculates the market-clearing price.

The objective function of the lower-level problem, Equation (4), is formulated using two terms. The first term represents the generation costs of power plants. The second term represents annualized investment costs for building the candidate power plants.

Equation (5) represents the supply-demand balance constraint and the dual variable $\left(\lambda_{y}\right)$ in this equation corresponds to the market-clearing price of the year $y$. Equation (6) represents peak demand constraint and the corresponding dual variable is $\lambda_{y}^{P}$. Inequalities in constraint Equation (7) enforce that the power produced in each year should not exceed the newly installed capacities in that year 
Table 2. Nomenclature

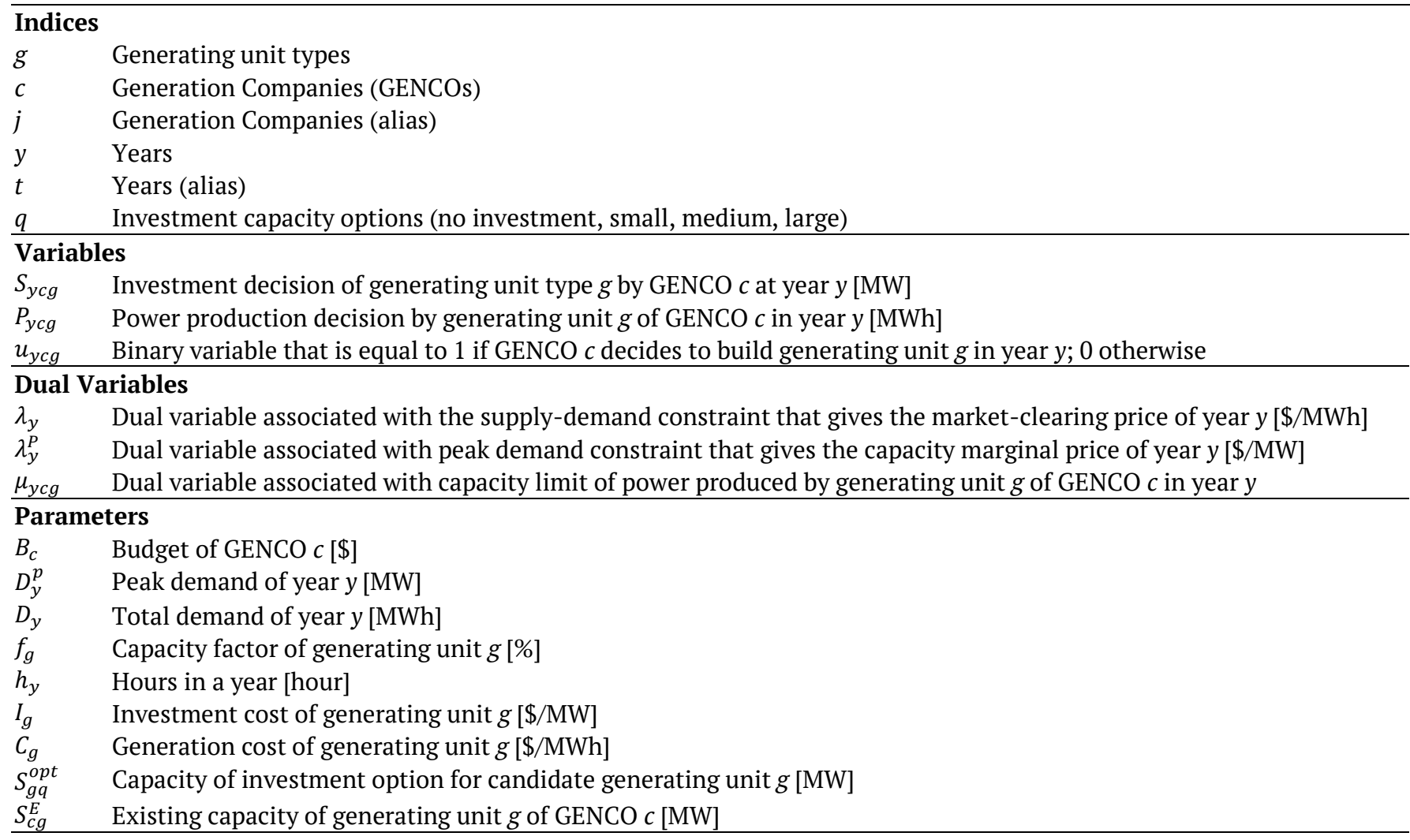

and installed capacities in previous years and the corresponding dual variable is $\mu_{y c g}$.

$$
\begin{gathered}
\min \sum_{g} C_{g} P_{y c g}+\sum_{g} I_{g} S_{y c g} \forall y, c \\
\sum_{c} \sum_{g} P_{y c g}=D_{y} \forall y, c: \lambda_{y} \\
\sum_{c} \sum_{g}\left(S_{c g}^{E}+\sum_{t=1}^{y} S_{y c g}\right) \geq D_{y}^{P} \forall y, c: \lambda_{y}^{P} \\
P_{y c g} \leq\left(S_{c g}^{E}+\sum_{t=1}^{y} S_{t c g}\right) h_{y} f_{g} \forall y, c, g: \mu_{y c g}
\end{gathered}
$$

\section{Equivalent Single Level Formulation}

The lower-level problem is a linear programming problem. Using the primal-dual formulation and replacing them with the first-order optimality conditions, the dual problem for the lower-level is formulated as follows:

$$
\begin{gathered}
\max D_{y} \lambda_{y}+\left(D_{y}^{p}-\sum_{c} \sum_{g} S_{c g}^{E}\right) \lambda_{y}^{P}-\sum_{g} S_{c g}^{E} h_{y} f_{g} \mu_{y c g} \forall g, y, c \\
\lambda_{y}-\mu_{y c g} \leq C_{g} \forall g, y, c \\
\lambda_{y}^{P}-h_{f} f_{g} \mu_{y c g} \leq I_{g} \forall g, y, c \\
\mu_{y c g} \geq 0 \forall g, y, c
\end{gathered}
$$

The two-level model is converted into a single-level model following these steps:

- The objective function of the upper-level problem, Equation (1) becomes the objective function of the single-level formulation, Equation (12) below.
- The constraint in Equation (2) in the upper-level problem holds as a constraint in the single-level as Equation (13).

- Constraints of the lower-level problem also remain as constraints in the single-level as Equations (14) to (16).

- The dual constraints of the lower-level problem, Equations $(9,10,11)$ above, become constraints in Equation (17) to (19) for the single-level.

- The objective function of the lower-level Equation (4) and the objective function of the dual problem for the lower-level Equation (8) are equaled and become the strong duality equality as in Equation (20).

$$
\begin{aligned}
& \min \sum_{y} \sum_{c}\left(D_{y}^{p}-\sum_{j, j \neq c} \sum_{g}\left(S_{j g}^{E}+S_{y j g}\right)\right) \\
& \sum_{y} \sum_{g} I_{g} S_{y c g} \leq B_{c} \forall c \\
& \sum_{c} \sum_{g} P_{y c g}=D_{y} \forall y, c \\
& \sum_{c} \sum_{g}\left(S_{c g}^{E}+\sum_{t=1}^{y} S_{y c g}\right) \geq D_{y}^{P} \forall y, c \\
& P_{y c g} \leq\left(S_{c g}^{E}+\sum_{t=1}^{y} S_{t c g}\right) h_{y} f_{g} \forall y, c, g \\
& \lambda_{y}-\mu_{y c g} \leq C_{g} \forall y, c, g \\
& \lambda_{y}^{P}-h_{y} f_{g} \mu_{y c g} \leq I_{g} \forall y, c, g \\
& \mu_{y c g} \geq 0 \forall g, y, c
\end{aligned}
$$


Table 3. The characteristics of existing power plants

\begin{tabular}{ccc}
\hline Type of power plants & Available capacity of 1 unit (MW) & Operation and maintenance cost (\$/MWh) \\
\hline Coal\# 1 & 300 & 30 \\
\hline Coal\#2 & 400 & 25 \\
\hline Gas turbine & 250 & 45 \\
\hline Oil & 200 & 50 \\
\hline CCGT & 250 & 35 \\
\hline
\end{tabular}

Table 4. The characteristics of the three optional candidate technologies

\begin{tabular}{ccccc}
\hline Type of Technology & \multicolumn{2}{c}{ Available capacity of $\mathbf{1}$ unit (MW) } & Investment cost (\$/MW) \\
\hline Tech\#1 & 100 & 150 & 200 & 500,000 \\
\hline Tech\#2 & 100 & 125 & 150 & 800,000 \\
\hline Tech\#3 & 100 & 150 & 200 & $1,000,000$ \\
\hline
\end{tabular}

$$
\begin{aligned}
\sum_{g} C_{g} P_{y c g}+\sum_{g} I_{g} S_{y c g} & =D_{y} \lambda_{y}+\left(D_{y}^{p}-\sum_{c} \sum_{g} S_{c g}^{E}\right) \lambda_{y}^{P} \\
& -\sum_{g} S_{c g}^{E} h_{y} f_{g} \mu_{y c g} \forall y, c
\end{aligned}
$$

Equivalent MILP Formulation

In the bi-level and single-level formulations, the investment decision variable, $S_{y c g}$, is a continuous variable. However, in real-world problems, it is generally a discrete variable, therefore, $S_{y c g}$ is reformulated as follows:

$$
\begin{gathered}
S_{y c g}=\sum_{q} u_{y c g q} S_{g q}^{o p t} \forall y, c, g \\
\sum_{q} u_{y c g q}=1 \forall y, c, g \\
u_{y c g q} \in\{0,1\} \forall y, c, g, q
\end{gathered}
$$

Adding Equations $(21,22,23)$ to the single level formulation, the equivalent MILP is formulated as in Equations (24) to (35). In this formulation, (24) to (32) are the same as in the single-level formulation. Equations (21, 22, 23) are added to the single level formulation as Equation (33) to (35) and the MILP model is formed as follows:

$$
\begin{aligned}
& \min \sum_{y} \sum_{c}\left(D_{y}^{p}-\sum_{j, j \neq c} \sum_{g}\left(S_{j g}^{E}+S_{y j g}\right)\right) \\
& \sum_{y} \sum_{g} I_{g} S_{y c g} \leq B_{c} \forall c \\
& \sum_{c} \sum_{g} P_{y c g}=D_{y} \forall y, c \\
& \sum_{c} \sum_{g}\left(S_{c g}^{E}+\sum_{t=1}^{y} S_{y c g}\right) \geq D_{y}^{P} \forall y, c \\
& P_{y c g} \leq\left(S_{c g}^{E}+\sum_{t=1}^{y} S_{t c g}\right) h_{y} f_{g} \forall g, y, c \\
& \lambda_{y}-\mu_{y c g} \leq C_{g} \forall g, y, c \\
& \lambda_{y}^{P}-h_{f} f_{g} \mu_{y c g} \leq I_{g} \forall g, y, c \\
& \mu_{y c g} \geq 0 \forall g, y, c \\
& \sum_{g} C_{g} P_{y c g}+\sum_{g} I_{g} S_{y c g}=D_{y} \lambda_{y}+\left(D_{y}^{p}-\sum_{c} \sum_{g} S_{c g}^{E}\right) \lambda_{y}^{P} \\
& -\sum_{g} S_{c g}^{E} h_{y} f_{g} \mu_{y c g} \forall y, c \\
& S_{y c g}=\sum_{q} u_{y c g q} S_{g q}^{o p t} \forall y, c, g
\end{aligned}
$$

$$
\begin{gathered}
\sum_{q} u_{y c g q}=1 \forall y, c, g \\
u_{y c g q} \in\{0,1\} \forall y, c, g, q
\end{gathered}
$$

The MILP formulation is equivalent to the bi-level model and it can be solved using general MILP solvers such as the GAMS CPLEX solver. In the next section, we present the numerical example. Later, we utilize the MILP formulation for the numerical example to test the proposed model.

\section{NUMERICAL EXAMPLE}

A long-term GEP with 10 GENCOs is considered as a case study to test the effectiveness of the proposed model and to evaluate the results. The data is collected from Pereira and Saraiva (2010) and modified. The characteristics of existing power plants are presented in Table 3, and we assumed that the total existing capacity of all GENCOs is $11,900 \mathrm{MW}$. The planning horizon is 10 years and three power plants are considered as candidate technologies for expansion. The characteristics of these three optional candidate technologies are listed in Table 4. Operation and maintenance costs for the three candidate technologies are 45,30 , and $25 \$ / M W h$, respectively. The capacity factor of all technologies is $70 \%$. We assumed the peak demand and the demand in the initial year are 11,627 MW and 40,663,834 MWh, respectively. The peak demand and demand are both increased yearly by $4 \%$ over the planning horizon.

In the example problem, we assumed that the company with the highest installed power is GEN 1 with 2550 MW. The installed capacities of other companies are relatively low except for GEN 1 and GEN 4. In this problem, we can assume that GEN 1 is a corporation or government institution that rules the sector as a monopoly before liberalization. Therefore, in solving this sample problem, our main aim is to reduce the initial market power of GEN 1. In this context, two scenarios will be examined. In the first scenario, companies do not have a budget restriction. In this case, it is acknowledged that the state-owned company has continued influence in the market, that is, GEN 1 will partially be able to maintain its power by making new investments. In the second scenario, the state company does not invest anymore, that is, the budget of the GEN 1 is considered zero. 


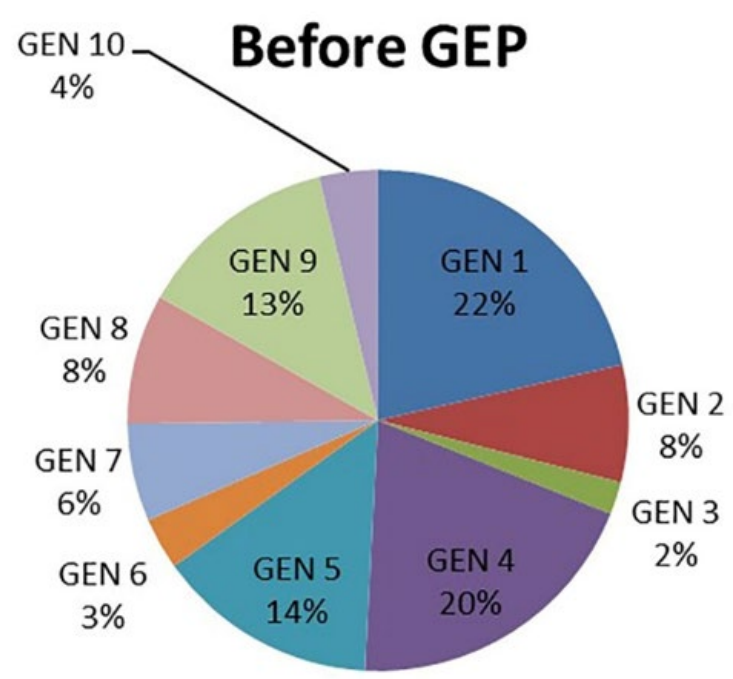

Figure 3. Initial capacity shares of all GENCOs

\section{RESULTS AND DISCUSSION}

The initial capacity shares of all companies before starting the GEP problem (at time zero, y0) are shown in Figure 3. The MILP model of the sample problem is solved using CPLEX 10.2 in GAMS. Figure 4 presents the comparison of the market power indices at the beginning (at time zero, y0) and after the GEP (y10). The market power index used here is the SMA index mentioned in the literature review and the model description, and it is calculated according to the following formula:

$$
\delta_{i}=D_{p}-\sum_{i} S_{-i}
$$

Here $\delta_{i}$ is the supply margin index for firm $i, D_{p}$ is the peak demand of the market, and $S_{-i}$ is the total production capacity of all firms except firm $i$. If $\delta_{i}$ is positive for any firm, the market power of that firm is at a level that will disrupt competition.

As can be seen from Figure 4, initially (at time zero, y0) every GENCO has more or less market power, except for GEN 3. Concerning the initially installed capacities, GEN 1 and GEN 3 are the strongest and the weakest, respectively. The market power indices before the GEP, for GEN 1 and GEN 3 are 2277 and -23 , respectively, meaning that GEN 1 is the strongest firm to distort competition.

In the first scenario, companies do not have a budget restriction. In this case, it is acknowledged that the stateowned company has continued influence in the market, that is, GEN 1 will partially be able to maintain its power by making new investments. In the second scenario, the state company does not invest anymore, that is, the budget of the GEN 1 is considered zero. After the GEP (y10), in the first scenario, the market power index of GEN 1 decreases to -4800.87 and the market power index of GEN 3 to $-10,550$. In the second scenario, the market power index of GEN 1 decreases to 4650.87 and the market power of GEN 3 to -6350.8 . As can be seen from the figure, in both scenarios, the market power indices of all firms are decreased below zero, and thus, there are no firms left that can distort competition. Market power distributions in the second scenario are relatively more balanced than in the first. The consequences of this will be better observed in other findings below.

Figure 5 compares the total installed capacities of all GENCOs before and after the GEP in percentage for the first and second scenarios. When the capacity shares are compared, it is seen that the companies that were small at the beginning have higher shares in the second scenario and the share of GEN

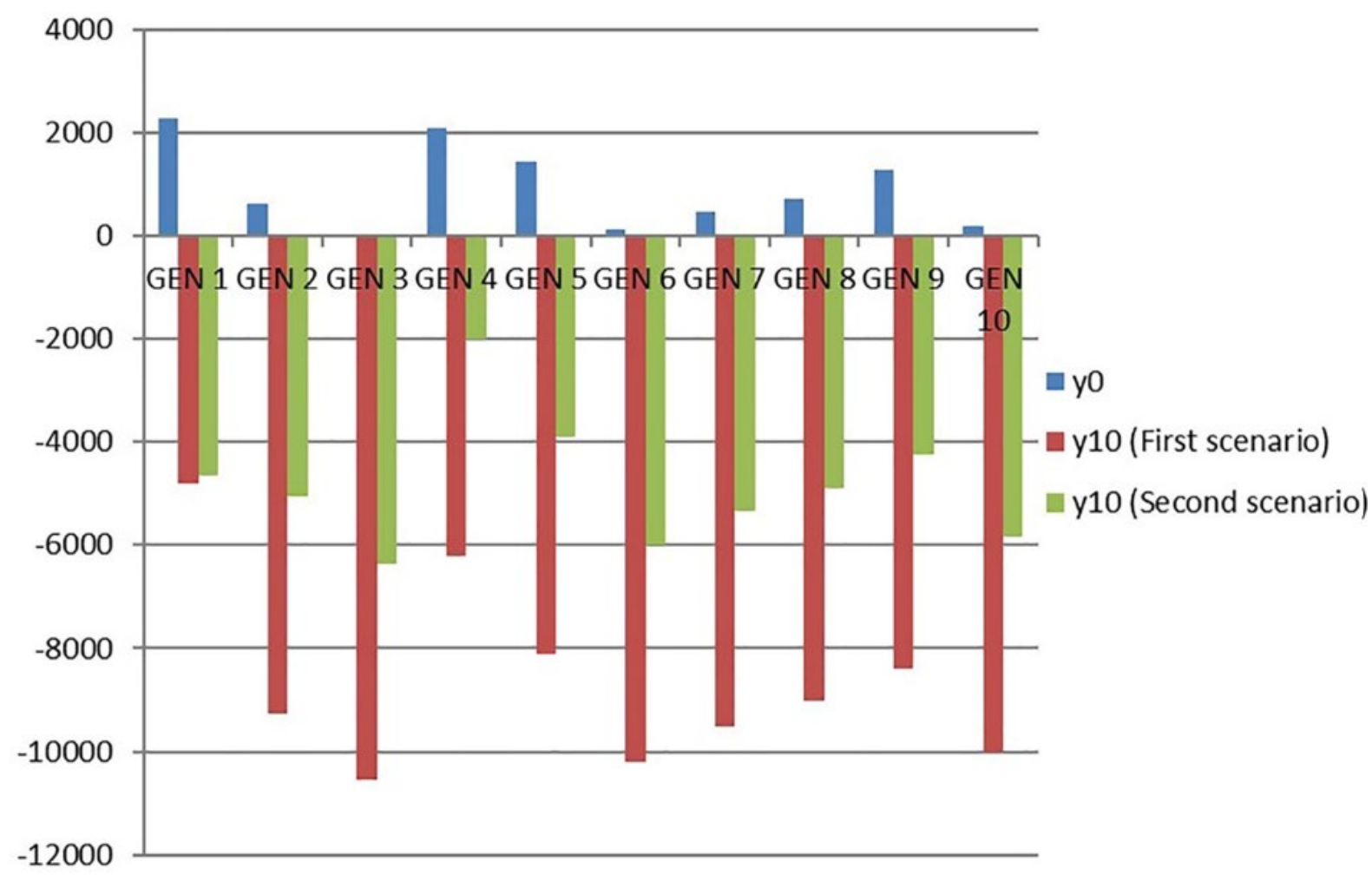

Figure 4. Comparison of the market power index for all GENCOs for years 0 and 10 (for both the first and the second scenario) 


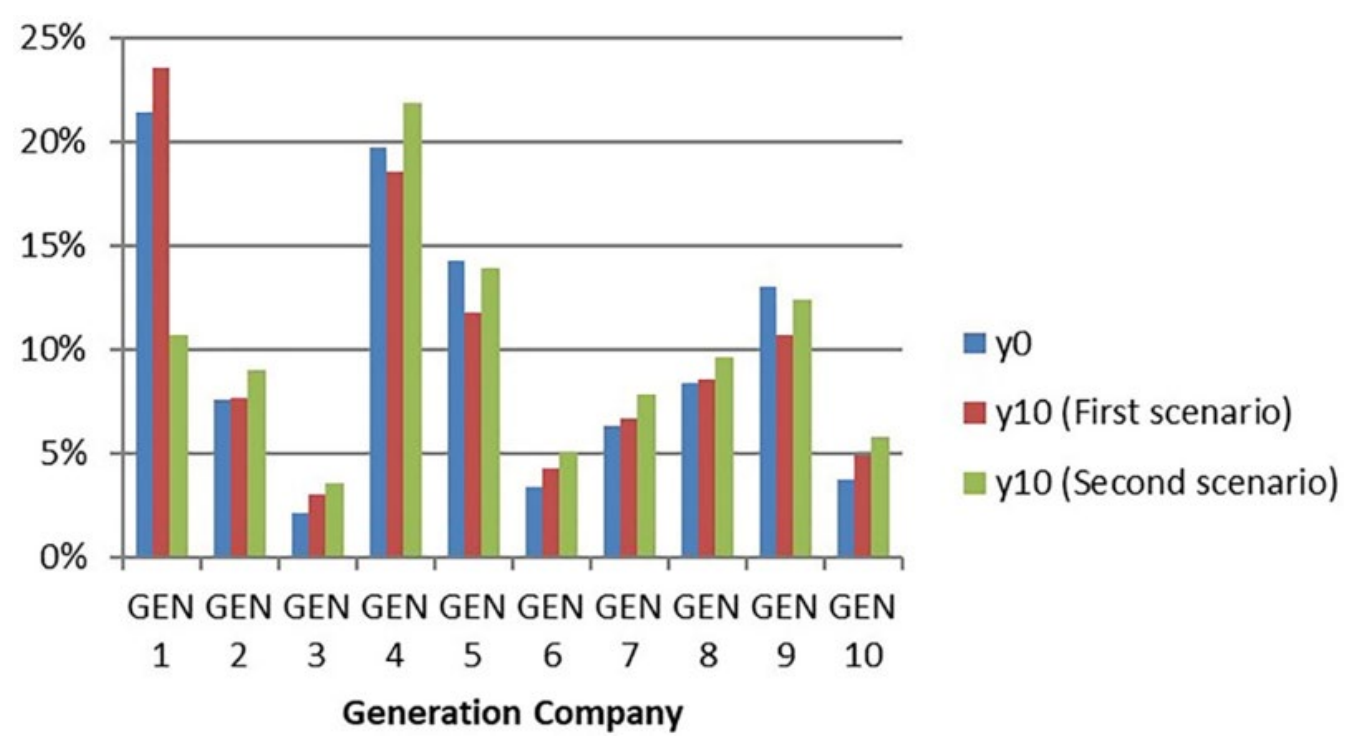

Figure 5. Percentage of total installed capacity of GENCOs before and after GEP

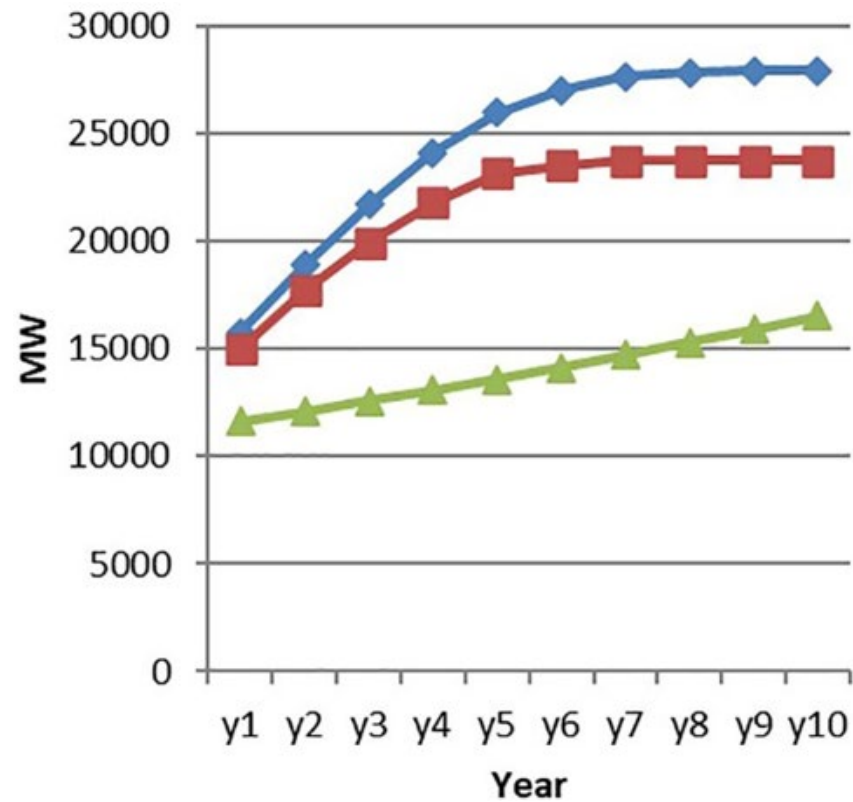

Figure 6. Total installed capacities and peak demand

1 is decreased significantly. This suggests that limiting the budget of GEN 1 is more beneficial in balancing competition. Hence, the state company should not continue investments after the market starts operation. Even if the state company is privatized before the deregulation or during the market and secures its full capacity and continues investment, the market power index still decreases as in the first scenario, and it has no power to distort competition. If the monopoly state firm is broken up to separate firms or its size is shrunk, then there is no problem for competition since it is exactly what we want. In this case, other firms might have higher capacities and market power, but our methodology can cope with it in both scenarios. For example, the market power index of GEN 4 is decreased to -6000 and -2000 in the first and second scenarios, respectively (Figure 4). That is, the second biggest company after the state firm is also restrained to distort competition.

Figure 6 shows the change in total installed capacity and peak demand over the years. In both scenarios, GENCOs are

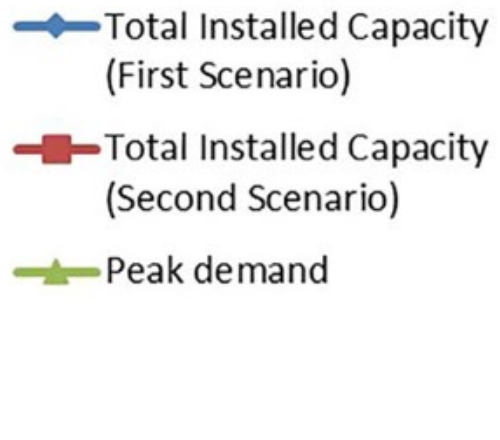

projected to invest well above the peak demand. But the second scenario was able to meet the investment needs from a lower level. Also, in the second scenario, investments were shifted to private firms (Figure 5), thus saving investment expenditures of both government and private firms. The second scenario is more successful in satisfying all actors.

Figure 7 shows the change in the market price of electricity. In both scenarios, prices tend to decrease toward the target year, but the second scenario can keep prices much lower for all years due to the effect of savings on investment expenditures. Price increases in years 2, 4, 5, 6 in the first scenario and years 3, 6, and 10 in the second scenario are due to the commissioning of investments and the relative decreases in the availability levels of installed power plants. These results show that the second scenario is more successful in satisfying not only the government and private companies but all actors, including consumers. Limiting the government's 


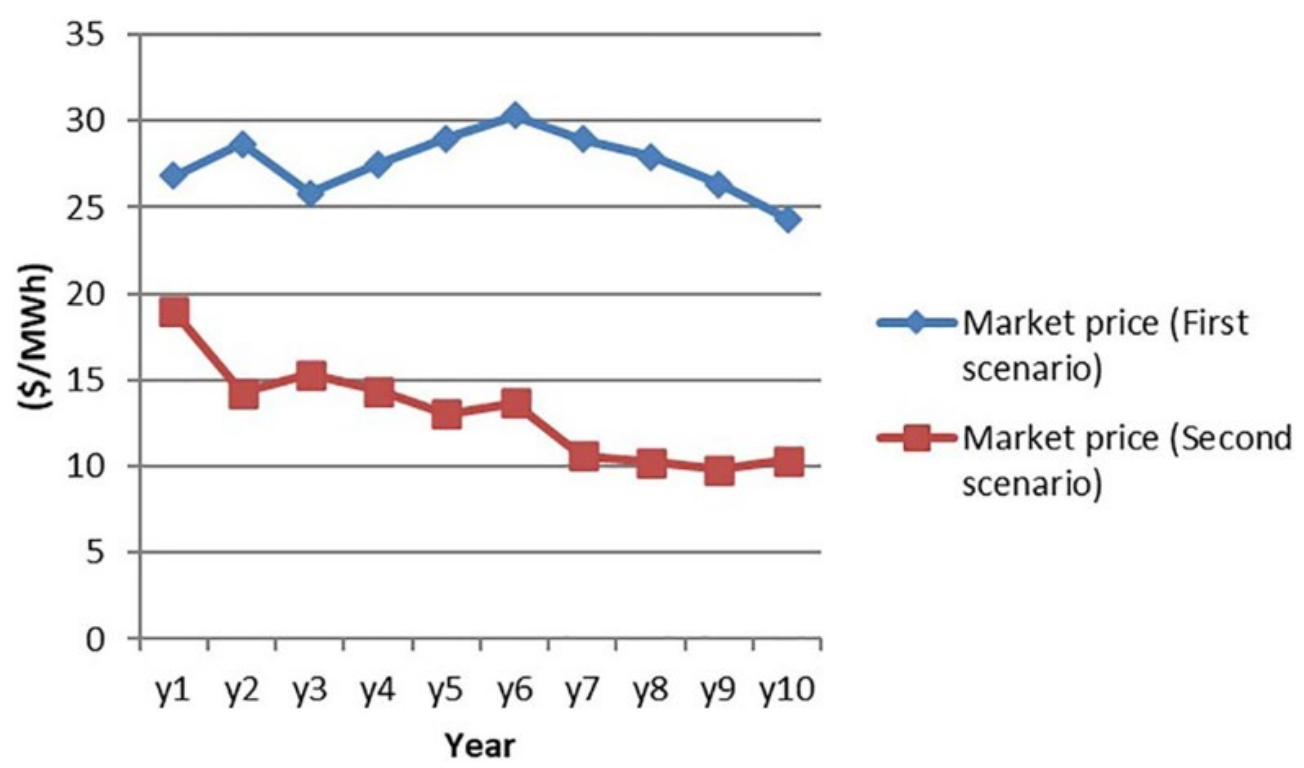

Figure 7. Market price for both scenarios

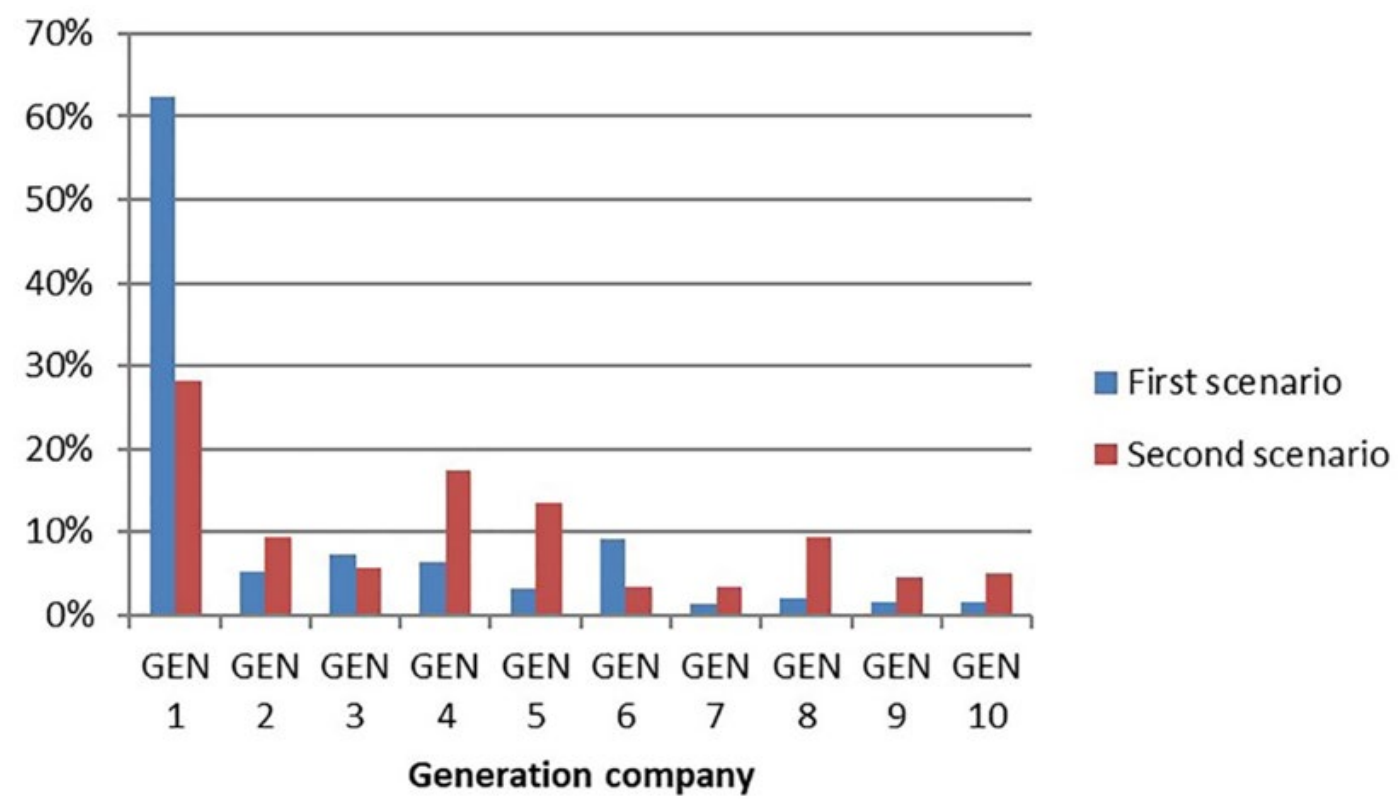

Figure 8. Total electricity generation of the GENCOs

intervention in the market and supporting GENCOs that were initially small are of great benefit in increasing competition.

The percentage shares of electricity generated by the GENCOs for a total of 10 years are presented in Figure 8. In the first scenario, the high share of GEN 1 in production is obvious. All other GENCOs shared the market with margins of 9\% or less. This is due to the higher initial capacity of GEN 1 than the others. However, the real difference is caused by the high investment share of GEN 1 in the first scenario in the following years. In the second scenario, market shares are more evenly distributed. GEN 1 is still the leading firm but it has a much lower share. The number of companies with a share of $9 \%$ and above is five in total. A balanced distribution of market share is also important for the following years. Since the companies will earn as much income as the electricity they sell, the income distribution of the companies will be fairer. Strong companies will not be able to drive the weak from the market. Furthermore, a fair distribution will encourage new companies to enter the market.

\section{CONCLUSION}

With the liberalization and opening of the electricity sector to competition, electricity markets have been established where private companies can produce and sell electricity. One of the main goals of this transformation is to increase efficiency and the other is to reduce electricity prices. To achieve these goals, the competitive environment in the markets must be maintained and developed. If one or more of the companies in the market use market power, competition in the market may decrease or disappear. In this case, the regulations and liberalization make no sense, while the efficiency drops to lower levels than before, and consumers have to buy electricity at higher prices. In this study, a MILP 
model is proposed to optimize the expansion planning that minimizes market power from the beginning of the electricity sector liberalization or after the markets start operation. In other words, the methodology can be utilized in the transition from monopoly to competitive electricity markets or the development process of the market. This model will assist decision-makers of governments, Independent System Operators, Regional System Operators, or other regulatory bodies in planning and implementing the transformation.

The lower-level problem of the proposed model aims at minimizing production and investment costs equivalent to maximizing social welfare. The top-level problem aims to minimize the market power of all companies to maximize competition. The bi-level formulation is first transformed to an equivalent single-level linear programming model using the primal-dual formulation at the lower level. In the second step, the continuous investment decision variable is converted to a discrete variable. Lastly, the equivalent MILP model is presented. The final MILP formulation is equivalent to the bilevel model and it can be solved using general MILP solvers This study is the first in the literature to directly aim for competition maximization.

To test and evaluate the effectiveness of the proposed model, a sample problem is solved for two different scenarios. In the first scenario, it is assumed that the state-owned company, a monopoly in the sector before liberalization, continues to invest in the market. In the second scenario, it is assumed that the state-owned company continues production but not investments. The findings show that the second scenario is more successful in terms of satisfying not only the state and private companies but also consumers. Limiting government intervention in the market and supporting companies that were initially small is of great benefit in increasing competition. Beyond the results of the study, we can argue that the state can divert its resources to other fields by investing less in the electricity sector. Private companies can make more investments and earn more in the market where the state's share is decreasing. Also, income distribution between companies can be achieved more equitably and consumers can get better quality service at lower prices.

Some assumptions have been made in the model and sample problem. For example, it has been ruled out that other companies could enter the market during the planning horizon. However, the results show that more firms entering the market will further strengthen the findings in this study.

Another assumption is that the proposed model is deterministic. In other words, the actors in the market have full knowledge of all parameters. Stochastic modeling is required to overcome this assumption and new solution techniques should be developed for this. Establishing a stochastic model for this problem is in the researchers' future work plan. On the other hand, the existing model can be used with different scenarios to partially model the uncertainties.

There are no network constraints in the proposed model, but these constraints do not change the overall results. Network constraints usually determine local competition and local prices in the market. Therefore, the model can be arranged to be used in examining the local competition.
One of the important assumptions of the model is that in the lower-level problem, minimization of production and investment costs that maximize social welfare is chosen as the goal. This assumption is justified for this study. However, the lower-level objective function may need to be changed to view the markets from different perspectives. For example, an important change from the perspective of companies would be to choose the profit maximization of companies rather than cost minimization as an objective function. Such a study is also among the plans of the authors.

Author contributions: All co-authors have involved in all stages of this study while preparing the final version. They all agree with the results and conclusions.

Funding: No external funding is received for this article.

Declaration of interest: The authors declare that they have no competing interests.

Ethics approval and consent to participate: Not applicable. Availability of data and materials: All data generated or analyzed during this study are available for sharing when appropriate request is directed to corresponding author.

\section{REFERENCES}

Conejo, A. J., Baringo, L., Kazempour, S. J. and Siddiqui, A. S. (2016). Investment in electricity generation and transmission. Cham Zug, Switzerland: Springer International Publishing. https://doi.org/10.1007/978-3319-29501-5

Ghaderi, A., Moghaddam, M. P. and Sheikh-El-Eslami, M. K. (2014). Energy efficiency resource modeling in generation expansion planning. Energy, 68, 529-537. https://doi.org/10.1016/j.energy.2014.02.028

Gonzalez-Romero, I. C., Wogrin, S. and Gómez, T. (2019). What is the cost of disregarding market feedback in transmission expansion planning? In 2019 International Conference on Smart Energy Systems and Technologies (SEST) (pp. 1-6). IEEE. https://doi.org/10.1109/ SEST.2019.8849107

Growitsch, C. and Nepal, R. (2009). Efficiency of the German electricity wholesale market. European Transactions on Electrical Power, 19(4), 553-568. https://doi.org/10.1002/ etep. 324

Hemmati, R., Hooshmand, R. A. and Khodabakhshian, A. (2013). Comprehensive review of generation and transmission expansion planning. IET Generation, Transmission \& Distribution, 7(9), 955-964. https://doi.org/10.1049/iet-gtd.2013.0031

Hobbs, B. F. (1995). Optimization methods for electric utility resource planning. European Journal of Operational Research, 83(1), 1-20. https://doi.org/10.1016/03772217(94)00190-N

Kagiannas, A. G., Askounis, D. T. and Psarras, J. (2004). Power generation planning: a survey from monopoly to competition. International Journal of Electrical Power \& Energy Systems, 26(6), 413-421. https://doi.org/10.1016/ j.ijepes.2003.11.003 
Kazempour, S. J., Conejo, A. J. and Ruiz, C. (2010). Strategic generation investment using a complementarity approach. IEEE Transactions on Power Systems, 26(2), 940-948. https://doi.org/10.1109/TPWRS.2010.2069573

Liu, F., Gou, J., Li, T., Wang, Y., Lei, Y., Liu, Y. and Wang, F. (2020). Bi-level Collaborative expansion planning for power grid and plants considering operational flexibility. In 2020 IEEE 4th Conference on Energy Internet and Energy System Integration (EI2) (pp. 2042-2046). IEEE. https://doi.org/10.1109/EI250167.2020.9346868

Mansur, E. T. (2008). Measuring welfare in restructured electricity markets. The Review of Economics and Statistics, 90(2), 369-386. https://doi.org/10.1162/rest.90.2.369

Müsgens, F. (2006). Quantifying market power in the German wholesale electricity market using a dynamic multiregional dispatch model. The Journal of Industrial Economics, 54(4), 471-498. https://doi.org/10.1111/j.14676451.2006.00297.x

Nazemi, A. and Mashayekhi, M. (2015). Competitiveness assessment of Iran's restructured electricity market. Energy Economics, 49, 308-316. https://doi.org/10.1016/j.eneco. 2015.02.019

Pedraza J. M. (2015). Electrical energy generation in Europe. The current situation and perspectives in the use of renewable energy sources and nuclear power for regional electricity generation. Springer International Publishing. https://doi.org/10.1007/978-3-319-16083-2

Pereira, A. J. and Saraiva, J. T. (2010). A decision support system for generation expansion planning in competitive electricity markets. Electric Power Systems Research, 80(7), 778-787. https://doi.org/10.1016/j.epsr.2009.12.003

Rafiei, S. A., Mohammadi-ivatloo, B., Asadi, S., Goldani, S. and Falaghi, H. (2019). Bi-level model for generation expansion planning with contract pricing of renewable energy in the presence of energy storage. IET Renewable Power Generation, 13(9), 1544-1553. https://doi.org/10.1049/ietrpg.2019.0074

Sadeghi, H., Rashidinejad, M. and Abdollahi, A. (2017). A comprehensive sequential review study through the generation expansion planning. Renewable and Sustainable Energy Reviews, 67, 1369-1394. https:/doi.org/10.1016/ j.rser.2016.09.046

Shukla, U. K. and Thampy, A. (2011). Analysis of competition and market power in the wholesale electricity market in India. Energy Policy, 39(5), 2699-2710. https://doi.org/10.1016/j.enpol.2011.02.039
Valinejad, J., Barforoshi, T., Marzband, M., Pouresmaeil, E., Godina, R. and PS Catalão, J. (2018b). Investment incentives in competitive electricity markets. Applied Sciences, 8(10), 1978. https://doi.org/10.3390/app8101978

Valinejad, J., Marzband, M., Barforoshi, T., Kyyrä, J. and Pouresmaeil, E. (2018a). Dynamic stochastic EPEC model for competition of dominant producers in generation expansion planning. In 2018 5th International Symposium on Environment-Friendly Energies and Applications (EFEA) (pp. 1-5). IEEE. https://doi.org/10.1109/EFEA.2018. 8617107

Wang, J., Shahidehpour, M., Li, Z. and Botterud, A. (2009). Strategic generation capacity expansion planning with incomplete information. IEEE Transactions on Power Systems, 24(2), 1002-1010. https://doi.org/10.1109/ TPWRS.2009.2017435

Wang, Q. and Chen, Z. (2019). Risk-based integrated generation and transmission planning of gas-electricity interdependent systems. In 2019 IEEE Power \& Energy Society General Meeting (PESGM) (pp. 1-5). IEEE. https://doi.org/10.1109/PESGM40551.2019.8973697

Wang, Y., Liu, S., Wang, J. and Zeng, B. (2018). Capacity expansion of wind power in a market environment with topology control. IEEE Transactions on Sustainable Energy, 10(4), 1834-1843. https://doi.org/10.1109/TSTE.2018. 2873646

Wogrin, S., Barquín, J. and Centeno, E. (2012). Capacity expansion equilibria in liberalized electricity markets: an EPEC approach. IEEE Transactions on Power Systems, 28(2), 1531-1539. https://doi.org/10.1109/TPWRS.2012.2217510

Wogrin, S., Centeno, E. and Barquín, J. (2011). Generation capacity expansion in liberalized electricity markets: A stochastic MPEC approach. IEEE Transactions on Power Systems, 26(4), 2526-2532. https://doi.org/10.1109/ TPWRS.2011.2138728

Wolak, F. A. (2015). Measuring the competitiveness benefits of a transmission investment policy: The case of the Alberta electricity market. Energy Policy, 85, 426-444. https://doi.org/10.1016/j.enpol.2015.05.024

Zhan, Y. and Zheng, Q. P. (2018). A multistage decisiondependent stochastic bilevel programming approach for power generation investment expansion planning. IISE Transactions, 50(8), 720-734. https://doi.org/10.1080/ 24725854.2018.1442032 